Received: 29 March 2017

Accepted: 17 July 2017

Published online: 23 August 2017

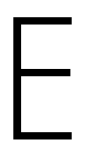

C N

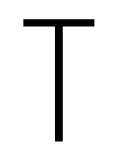

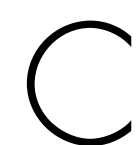

REP

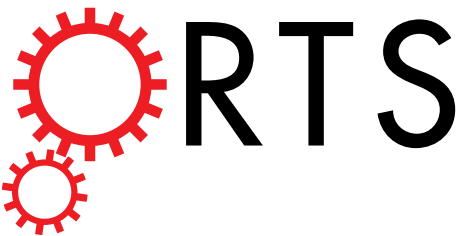

OPEN

\title{
The small GTPase, nucleolar GTP- binding protein 1 (NOG1), has a novel role in plant innate immunity
}

Seonghee Lee ${ }^{1,2}$, Muthappa Senthil-Kumar ${ }^{1,6}$, Miyoung Kang ${ }^{3}$, Clemencia M. Rojas ${ }^{1,5}$, Yuhong Tang $^{1}$, Sunhee $\mathrm{Oh}^{1}$, Swarup Roy Choudhury ${ }^{4}$, Hee-Kyung Lee ${ }^{1}$, Yasuhiro Ishiga ${ }^{1,7}$, Randy D. Allen $^{3}$, Sona Pandey ${ }^{4}{ }^{4}$ \& Kirankumar S. Mysore ${ }^{1}$

Plant defense responses at stomata and apoplast are the most important early events during plantbacteria interactions. The key components for the signaling of stomatal defense and nonhost resistance have not been fully characterized. Here we report the newly identified small GTPase, Nucleolar GTPbinding protein 1 (NOG1), functions for plant immunity against bacterial pathogens. Virus-induced gene silencing of $N O G 1$ compromised nonhost resistance in $N$. benthamiana and tomato. Comparative genomic analysis showed that two NOG1 copies are present in all known plant species: NOG1-1 and NOG1-2. Gene downregulation and overexpression studies of NOG1-1 and NOG1-2 in Arabidopsis revealed the novel function of these genes in nonhost resistance and stomatal defense against bacterial pathogens, respectively. Specially, NOG1-2 regulates guard cell signaling in response to biotic and abiotic stimuli through jasmonic acid (JA)- and abscisic acid (ABA)-mediated pathways. The results here provide valuable information on the new functional role of small GTPase, NOG1, in guard cell signaling and early plant defense in response to bacterial pathogens.

Plant pathogens that are able to cause disease in a given plant species are considered host pathogens while those that are unable to do so are nonhost pathogens. Nonhost resistance is a more wide-spread and durable plant defense mechanism that is achieved by a combination of preformed and inducible defenses ${ }^{1,2}$. Preventing the entry of the pathogen into plant tissue is one of the key aspects of nonhost resistance, also known as stomatal innate immunity ${ }^{3-6}$.

In contrast to many fungal pathogens that are able to penetrate the plant epidermis, bacterial pathogens rely on wounds or natural openings to enter the apoplast ${ }^{7,8}$. One well-characterized means of entry is through the stomata, microscopic pores on the plant surface that allow gas exchange between plant tissues and the atmosphere. Stomatal opening and closure depend on the environmental and physiological conditions of the plant and are regulated by two guard cells that surround the pore. ${ }^{9}$ Pathogen Associated Molecular Patterns (PAMPs) such as flagellin-derived peptide flg22 and the bacterial lipopolysaccharide (LPS) can trigger stomatal closure . However, adapted plant bacterial pathogens are able to re-open stomata by means of virulence factors such as the phytotoxin coronatine (COR), a mimic of the active JA-Ile hormone ${ }^{4,7}$. In the absence of COR, transcription factors related to JA signaling such as MYC2 interact with a repressor complex formed by Jasmonate-Zim domain (JAZ) to repress transcription of JA-responsive genes ${ }^{10}$. In the presence of COR, JAZ proteins bind the F-box protein Coronatine insensitive 1 (COI1), a subunit of an E3 ubiquitin ligase complex, and are subjected to 26S proteasome-mediated degradation ${ }^{11}$. Although JA regulated genes play a critical role in JA-mediated guard cell signaling pathway and stomatal immunity, it still remains unclear what genetic components are directly implicated in this sophisticated network that regulate stomatal defense against bacterial pathogens. In the present study, we identified two small G-proteins, Nucleolar GTP-binding protein 1-1 (NOG1-1) and 1-2 (NOG1-2), which play an important role in the regulation of nonhost resistance and stomatal defense against bacterial pathogens.

${ }^{1}$ Noble Research Institute, LLC, Ardmore, Oklahoma, USA. ${ }^{2}$ Gulf Coast Research and Education Center, Institute of Food and Agricultural Science, University of Florida, Balm, Florida, USA. ${ }^{3}$ Institute for Agricultural Biosciences, Oklahoma State University, Ardmore, Oklahoma, USA. ${ }^{4}$ Donald Danforth Plant Science Center, St. Louis, Missouri, USA. ${ }^{5}$ Present address: Department of Plant Pathology, University of Arkansas, Fayetteville, Arkansas, USA. ${ }^{6}$ Present address: National Institute of Plant Genome Research, Aruna Asaf Ali Marg, New Delhi, India. ${ }^{7}$ Present address: Department of Plant Pathology, University of Tsukuba, Ibaraki, Japan. Correspondence and requests for materials should be addressed to K.S.M. (email: ksmysore@noble.org) 
G-proteins are GTP-binding proteins with GTPase activity that act as molecular switches to regulate diverse cellular processes by alternating between an active conformation (GTP-bound) and an inactive conformation (GDP-bound) ${ }^{12}$. Small monomeric G-proteins, also known as small GTPases, are widely conserved in eukaryotes and regulate many essential cellular processes ${ }^{13}$. Based on their function, these small GTPases are classified as: ADP ribosylation factor (ARF), Ras-related in brain (RAB), Ras-related nuclear protein (RAN), rat sarcoma (RAS) and $\mathrm{RHO}^{14}$. A number of RHO family of small GTPases are well known as the key regulator of immunity in plants and animals ${ }^{15}$. Some of the small RAB GTPases have been described for their important role for SA- and JA-mediated defense signaling, and stomatal immunity ${ }^{16-18}$. On the other hand, the family of TRAFAC (translation factors) belonging to the superclass of P-loop GTPases is a novel group of G-proteins, initially identified by analyzing fully sequenced bacterial genomes and essential for cell viability, and distinct from the small GTPases commonly present in plants ${ }^{19-21}$. The TRAFAC class is divided into seven families: TrmE (Probable tRNA modification GTPase in E. coli), Era (E. coli Ras-like protein), YfgK, YihA, OBG, Hflx and classic translation factor family ${ }^{19}$. The orthologs of these organelle-targeted small GTPases were found in plants, suggesting the horizontal transfer of eubacteria-derived small GTPases into plants. Most of them are localized to chloroplasts and/or mitochondria, while only the archaea-related GTPases in OBG and ERA family are localized to the cytoplasm and nucleus. In Arabidopsis, 18 GTPases belonging to the TRAFAC class have been identified ${ }^{20}$. The Arabidopsis NOG1-1 and NOG1-2 belongs to the OBG family that has been known to regulate ribosome biogenesis and RNA modification in yeast and bacteria. Recently, subcellular localization studies showed that NOG1 homologs in Arabidopsis were localized to the nucleus ${ }^{22}$. However, their biological functions are largely unknown in plants ${ }^{23-25}$. In this study, we showed that NOG1-1 and NOG1-2 are involved in plant defense against bacterial pathogens.

\section{Results}

NOG1 is involved in nonhost resistance in Nicotiana benthamiana and tomato. A Tobacco rattle virus (TRV)-based virus-induced gene silencing (VIGS)-mediated fast forward genetics approach was used in $N$. benthamiana to identify plant genes that play a role in nonhost resistance against bacterial pathogens ${ }^{26}$. One of the cDNAs identified from this approach had homology to the functionally uncharacterized gene with a small GTPase domain, NOG1. Upon inoculation with the nonhost pathogen Pseudomonas syringae pv. tomato T1, bacterial multiplication was significantly increased ( $>4$ logs) in the inoculated leaves when compared to the non-silenced control (TRV::00) that was asymptomatic (Fig. 1A).

To assess how broad the NOG1-mediated nonhost resistance was, NbNOG1-silenced N. benthamiana plants were further analyzed for their response to additional nonhost pathogens such as $P$. syringae pv. glycinea (a soybean pathogen) and Xanthomonas campestris pv. vesicatoria (a pepper pathogen). The down-regulation of NbNOG1 was confirmed in NbNOG1-silenced N. benthamiana plants (Fig. S1A). Both pathogens multiplied to significantly higher levels at 7 days post-inoculation (dpi) in NOG1-silenced plants compared to wild-type and non-silenced control plants (Fig. S1B,C). Inoculation with the host pathogen P. syringae pv. tabaci caused disease symptoms and bacterial multiplication in both NbNOG1-silenced plants and non-silenced controls with no significant difference at $5 \mathrm{dpi}$ although more number of bacteria were found in infected leaves at $2 \mathrm{dpi}$ (Fig. 1B).

To determine whether downregulation of NOG1 impairs elicitation of the hypersensitive response (HR), a visual inspection of HR symptom development was performed in NbNOG1-silenced and control plants after infiltration with high inoculum of the nonhost pathogens $P$. syringae pv. tomato T1 and X. campestris pv. vesicatoria, or by transient co-expression of the resistance $(R)$ genes Pto or $C f 9$ with their corresponding avirulence genes AvrPto or AvrCf9, respectively, or by transient expression of the PAMP elicitor INF1. HR symptoms were observed in the control plants but not in the NbNOG1-silenced plants at the time points tested (Fig. 1C), suggesting that NOG1 also plays a role in elicitation of the HR triggered by nonhost pathogens, gene-for-gene interactions and PAMPs.

To determine if NOG1 is involved in nonhost resistance in other plant species, we used N. benthamiana NOG1 to silence its orthologous gene in tomato (SINOG1) by VIGS. SINOG1-silenced tomato plants and non-silenced control were inoculated with the tomato nonhost pathogen $P$. syringae pv. tabaci that causes fire blight disease in tobacco. Similar to the findings in N. benthamiana, downregulation of SINOG1 compromised nonhost disease resistance in tomato resulting in disease symptoms and increased bacterial multiplication when compared to the control (Fig. 2A). Inoculation with the host pathogen P. syringae pv. tomato DC3000 caused slightly more severe disease symptoms accompanied with a higher bacterial titer in the SINOG1-silenced plants than in control plants (Fig. 2B). Taken together, these results suggest that NOG1 is required for nonhost resistance against bacterial pathogens in N. benthamiana and tomato.

NOG1-1 and NOG1-2 are members of the small GTP-binding family proteins OBG in Arabidopsis. NbNOG1 showed a high degree of similarity to proteins belonging to the small GTP-binding family protein OBG such as yeast Nog1p (42.7\%) and human GTP binding protein 4 (GTPBP4; 48.6\%) (Fig. S2A and Table S1). Sequence homologs of NOG1 were identified in a wide range of plant species. Two copies of NbNOG1 or SINOG1 with nucleotide identity of $99.1 \%$ and $97.5 \%$ were identified in N. benthamiana and tomato, respectively. We identified two Arabidopsis genes, At1g50920 (NOG1-1) and At1g10300 (NOG1-2), as NbNOG1 homologs. Both genes are 79\% identical at the nucleotide level and 76\% similar at the amino acid level, suggesting the selection for functional divergence and adaptation. Using the GTPase domain sequence of NOG1-1 and NOG1-2, a total of 10 orthologs were identified in Arabidopsis. Phylogenetic analysis revealed that NOG1-1 and NOG1-2 are highly similar to small GTP-binding family proteins Obg, DRG, and ERG in Arabidopsis (Fig. S2B). Annotation of the NOG1-2 sequence in The Arabidopsis Information Resource (TAIR; www.arabidopsis.org) showed a 2,064 bps containing two exons and one intron that is predicted to encode a protein of 687 amino acids. However, results from reverse transcription-PCR (RT-PCR) of full length NOG1-2 followed by c-DNA 
$\mathbf{A}$

\section{P. syringae pv. tomato T1}
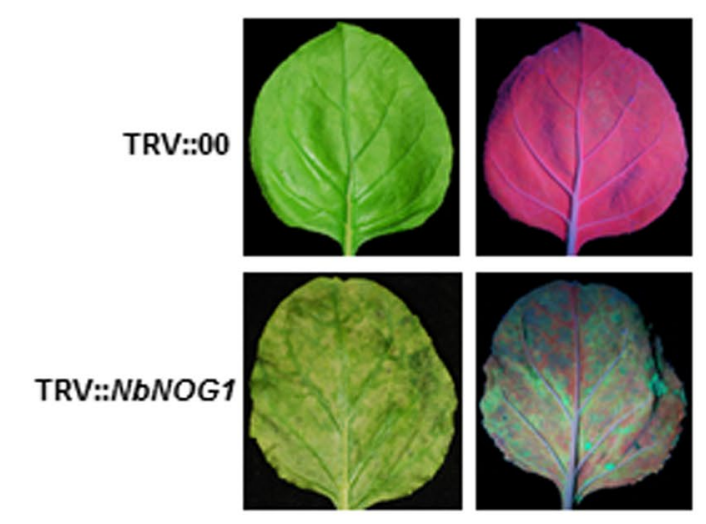

B
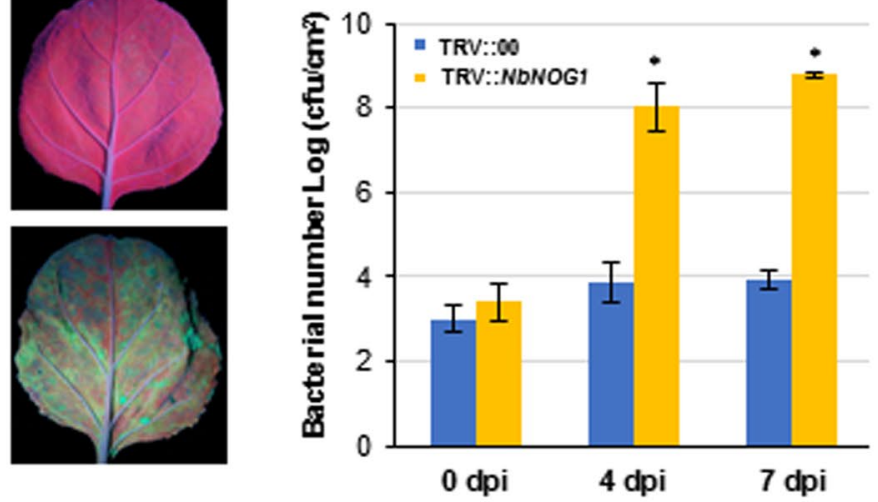

\section{P. syringae pv. tabaci}
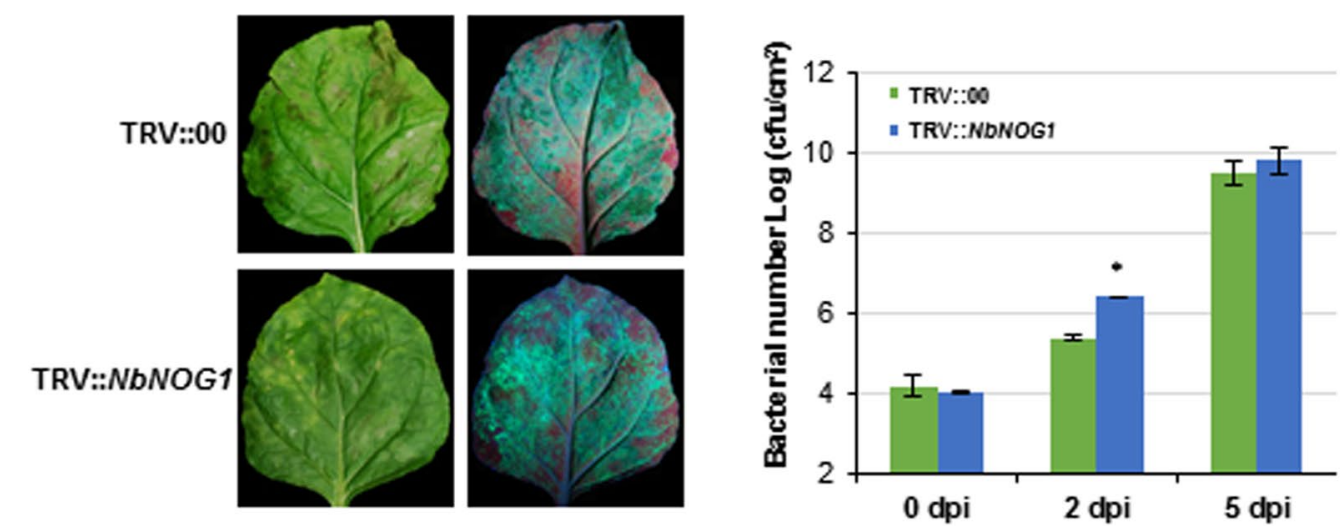

$\mathbf{C}$

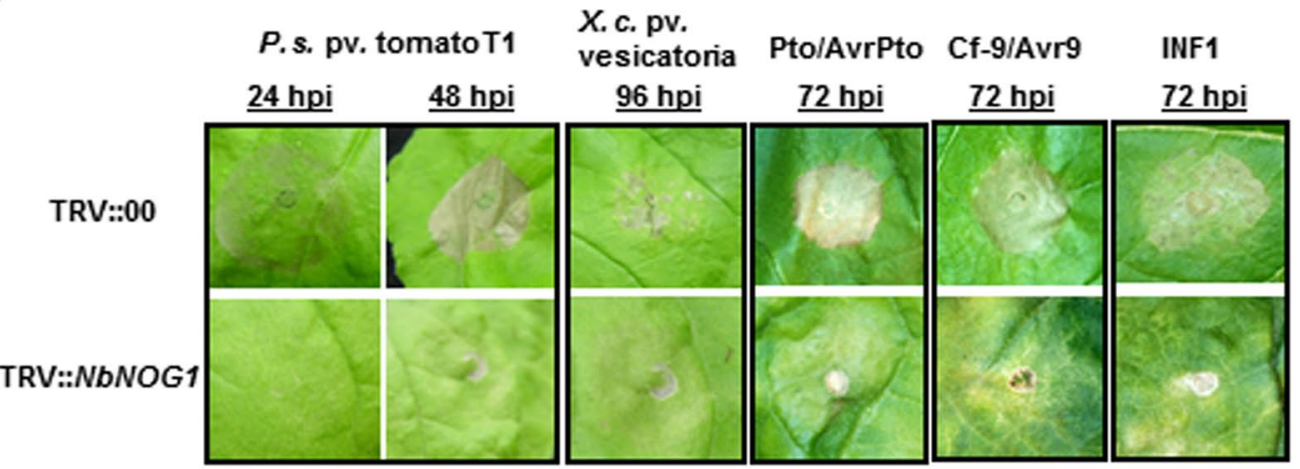

Figure 1. N. benthamiana NbNOG1-silenced plants are compromised in nonhost resistance. (A,B) NbNOG1silenced (TRV::NbNOG1) and non-silenced control (TRV::00) N. benthamiana plants were vacuum-infiltrated with nonhost pathogen $P$. syringae pv. tomato T1 $\left(p D S K-G F P_{u v}\right)$ or host pathogen $P$. syringae pv. tabaci $(p D S K-$ $G F P_{u v}$ ) to observe symptom development (left panels) or bacterial multiplication 3 days post-inoculation (dpi; right panels). An increase in GFP fluorescence associated with bacterial multiplication was observed in TRV::NbNOG1 plants but not in the TRV::00. To monitor bacterial multiplication in TRV::NbNOG1 and TRV::00, N. benthamiana plants were vacuum-infiltrated with P. syringae pv. tomato T1 (A) and P. syringae pv. tabaci (B) and bacterial multiplication was quantified at various dpi as indicated. Bars represent means and standard deviations for three independent experiments. Asterisks above bars indicate statistically significant difference between NbNOG1-silenced plants and control (Student's $t$-test $P<0.05$ ). (C) HR was observed between NbNOG1-silenced and control $N$. benthamiana plants. Plants were syringe-infiltrated with $P$. syringae pv. tomato T1 or X. campestris pv. vesicatoria $\left(1 \times 10^{6} \mathrm{CFU} / \mathrm{ml}\right)$ or Agrobacterium strains for transient expression of Pto and AvrPto, or Cf-9 and Avr-9, or INF1. Agrobacterium strain GV2260 with empty vector (EV) was used as a control. HR was observed at different hours post inoculation (hpi). This experiment was repeated at least three times and showed similar results. Each experiment had five replications. 
A

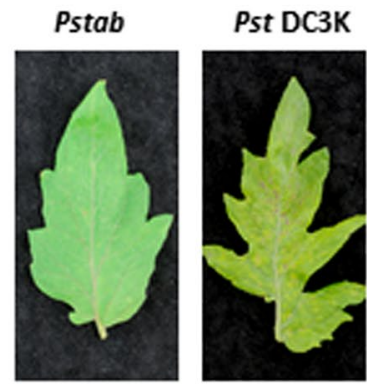

TRV::00

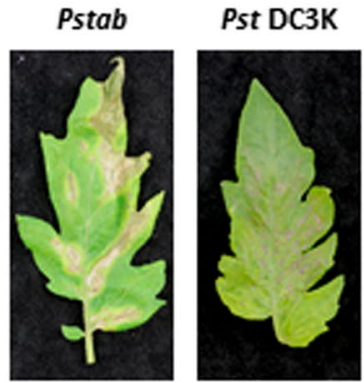

TRV::NbNOG1
B

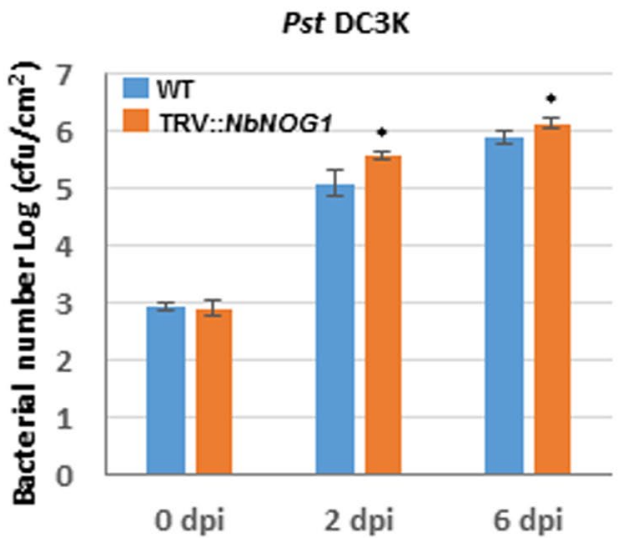

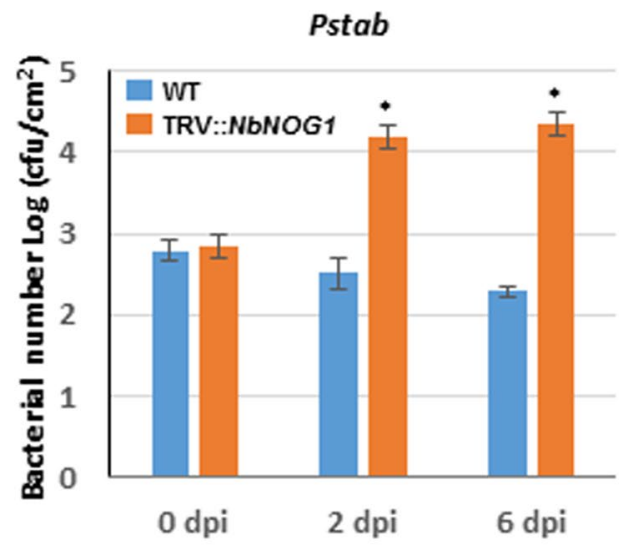

Figure 2. Tomato SlNOG1-silenced plants are compromised in nonhost resistance. (A) SlNOG1-silenced tomato compromised nonhost resistance. TRV::NbNOG1 and TRV::00 inoculated tomato plants were sprayed with the nonhost pathogen $P$. syringae pv. tabaci (Pstab) and the host pathogen P. syringae pv. tomato DC3000 (Pst DC3K). Pictures were taken after 5 days after inoculation. (B) The bacterial growth of both pathogens was significantly higher in SlNOG1-silenced plants than TRV::00 plants. Bacterial growth was measured after 2 and 6 dpi. Bars represent means and standard deviation for three independent experiments. Asterisks represent statistically significant difference between treatments for equivalent time points using Student's $t$ - test $(P<0.05)$.

synthesis and Sanger sequencing showed that no intron sequence was present, and it encodes a truncated protein with 346 amino acids. This was further confirmed by western blot analysis (Figs S3A and S6C). NOG1-2 protein of $\sim 40 \mathrm{kDa}$ was detected by GTPBP4 antibody (N-terminal region) in Arabidopsis and, as expected, His-tag fused NOG1-2 was $\sim 50 \mathrm{kDa}$. The reason why TAIR annotation shows the presence of an intron in NOG12 is due to the presence of a stop codon at the predicted intron. To investigate if the early termination occurs only in Col-0 or other Arabidopsis ecotypes, NOG1-2 amino acid sequences were examined in 19 representative different ecotypes. Interestingly, the truncated version of NOG1-2 is only present in Col-0, Ler-0, Rsch-4 and Wil-2 (Fig. S3B; Table S2). This early translational termination does not affect the GTPase domain. Furthermore, sequence alignment with NOG1-2 homologs of other eukaryotes suggested that the NOG1-2 start codon begins $87 \mathrm{bps}$ downstream of the start codon annotated by TAIR (Table S1). According to the protein expression results, the 87-bp deletion does not affect translation (Fig. S3A). This 87-bp deleted NOG1-2 was used for all experiments in this study. In contrast to NOG1-2, NOG1-1 sequences were highly similar among different ecotypes of Arabidopsis.

Expression of NOG1-1 and NOG1-2 are induced by biotic and abiotic stresses. The gene expression patterns of NOG1-1 and NOG1-2 were determined by quantitative RT-PCR (qRT-PCR) after treating wild-type Col-0 plants with ABA, PAMPs (Flg22 and LPS), host P. syringae pv. maculicola (Psm) and nonhost P. syringae pv. tabaci (Pstab) bacterial pathogens. NOG1-2 was induced $\sim 4$ fold at $12 \mathrm{~h}$ post treatment (hpt) with Flg22, 2 fold with ABA treatment at 6 hpt and $\sim 1$.5-fold after treatment with either the host or nonhost pathogens tested (Fig. 3A). NOG1-1 exhibited a more dynamic expression range and was highly induced at $12 \mathrm{hpt}$ with $\mathrm{ABA}, \mathrm{Flg} 22$, host and/or nonhost pathogens. Interestingly, at $24 \mathrm{hpt}$, the induction of NOG1-1 was reduced by more than $50 \%$ (Fig. 3A) in response to each of the treatments.

Arabidopsis lines expressing the $\beta$-glucuronidase (GUS) reporter gene under the control of NOG1-1 or NOG1-2 promoters showed expression of GUS in guard cells and hydathodes, which are the natural openings for the entry of bacterial pathogens (Fig. S4A,B). In addition, these lines showed distinct patterns of GUS expression 
NOG1-1

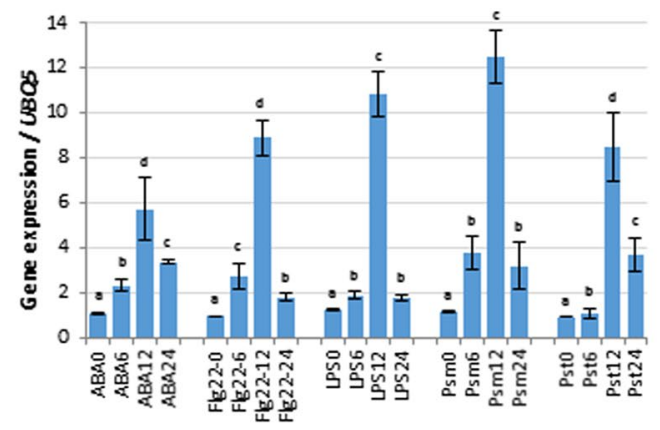

B

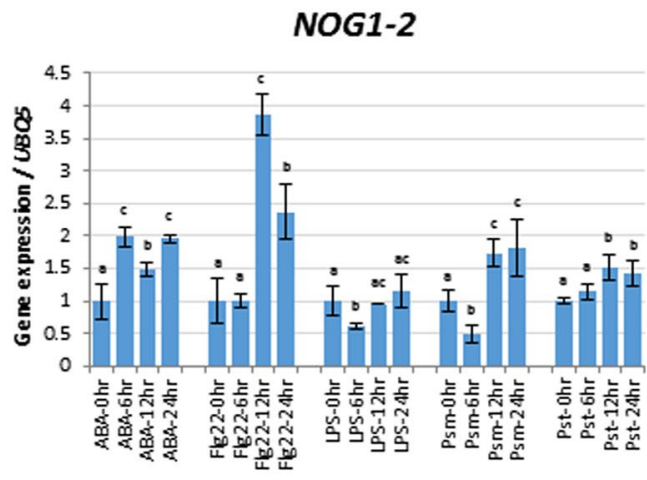

pNOG1-2::GUS

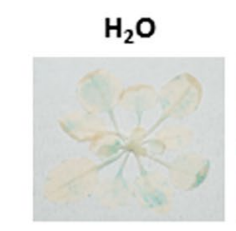

LPS

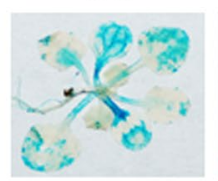

ABA

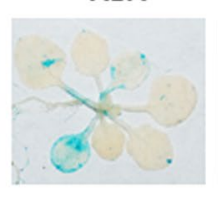

Psm

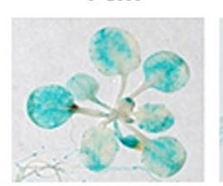

flg22

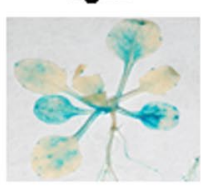

Pstab

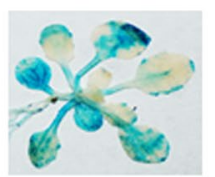

$\mathrm{H}_{2} \mathrm{O}$

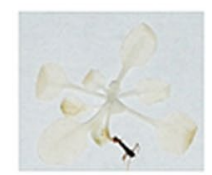

LPS
ABA

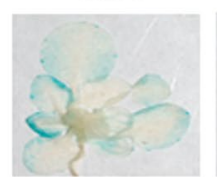

Psm

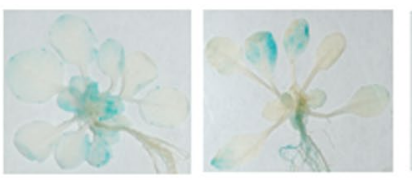

flg22

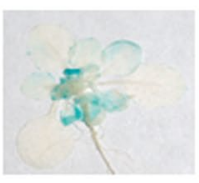

Pstab

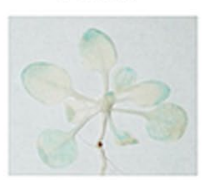

Figure 3. NOG1-1 and NOG1-2 are induced by ABA, PAMPs, host and nonhost bacterial pathogens. (A) Arabidopsis wild-type (Col-0) plants were individually syringe-infiltrated with ABA $(10 \mu \mathrm{M})$, Flg22 $(20 \mu \mathrm{M})$, or LPS (100ng), or flood-inoculated with the pathogens P. syringae pv. maculicola (Psm) and P. syringae pv. tabaci (Pstab) at $1 \times 10^{4} \mathrm{CFU} / \mathrm{ml}$. RNA was isolated from tissue samples harvested at $0 \mathrm{hr}, 6 \mathrm{hr}, 12 \mathrm{hr}$ and $24 \mathrm{hr}$, and qRT-PCR was performed. Bars indicate relative gene expression in comparison with the housekeeping gene Ubiquitin (UBQ5) and in relation to $0 \mathrm{hr}$ time that was considered as 1 . Different letters above bars indicate a statistically significant difference within a treatment using two-way ANOVA $(P<0.01)$. Error bars represent the standard deviation of three biological replicates (three technical replicates for each biological replicate). (B) $\beta$-Glucuronidase (GUS) staining of pNOG1-1::GUS and pNOG1-2::GUS in response to ABA, PAMPs, bacterial pathogens. pNOG1-1::GUS (left panel) and pNOG1-2::GUS (right panel) expression was measured 12 hr after treatment with ABA, flg22, LPS, Psm and Pstab. Seedlings were flood-inoculated with both pathogens $\left(1.4 \times 10^{6} \mathrm{CFU} / \mathrm{ml}\right), \mathrm{ABA}(10 \mu \mathrm{M})$ and PMAPs (flg22: $20 \mu \mathrm{M}$, and LPS: 100ng). After $2 \mathrm{hr}$ of GUS straining, plants were washed with sterile water and images were obtained.

of pNOG1-1-GUS and pNOG1-2-GUS in different tissues (Fig. S4). For example, NOG1-1 was expressed in the most parts of a flower, while NOG1-2 expression was only found in flower petal.

To verify the expression of NOG1-1 and NOG1-2 in vivo, the changes in GUS activity in the transgenic plants were determined following treatment of biotic and abiotic stimuli. As shown in Fig. 3A, both NOG1-1 and NOG12 expression were induced in response to ABA, PAMPs and bacterial pathogens (Fig. 3B). These results suggest that NOG1-1 and NOG1-2 are involved in defense responses to both biotic and abiotic stresses.

NOG1-1 is necessary for defense responses against bacterial pathogens. As described in Fig. 1, NbNOG1- and SlNOG1-silenced N. benthamiana and tomato plants, respectively, compromised nonhost resistance. The function of NOG1-1 and NOG1-2 for nonhost resistance was tested in Arabidopsis. Because nog11 T-DNA insertion mutants were not available, we generated RNA interference (RNAi) lines to downregulate NOG1-1 expression. Among 23 transgenic lines, two RNAi lines, RNAi2 and RNAi10, that showed $\sim 50 \%$ downregulation of NOG1-1 were selected for further experiments (Fig. S5A). The expression of NOG1-2 was not altered in NOG1-1-RNAi plants (Fig. S6B). Similar to NbNOG1- and SINOG1-silenced plants that showed stunted growth, NOG1-1-RNAi plants were slightly smaller than wild type (Fig. S5B).

In contrast to NOG1-1, a T-DNA insertion line for NOG1-2, SALK_043706, was identified and obtained from the Arabidopsis Biological Resource Center. T-DNA insertion is located at the $3^{\prime}$ UTR of the NOG1-2 gene, which 
presumably disrupts the poly adenylation signal and affects transcript stability (Fig. S6A). The qRT-PCR and western blot experiments showed that NOG1-2 transcripts and NOG1-2 protein were significantly reduced in SALK_043706 line (Fig. S6B,C). SALK_043706 (nog1-2) was transformed with a construct containing the NOG12 native promoter and coding region but without $3^{\prime} \mathrm{UTR}$ for a complementation experiment. NOG1-2 expression was slightly increased in the complemented line (NOG1-2-comp) but still comparable to the expression of NOG12 in Col-0 (Fig. S6B). In contrast to NOG1-1-RNAi plants, nog1-2 showed a wild-type phenotype. The number of stomata/leaf area was not different in NOG1-1 RNAi or nog1-2 plants when compared to Col-0. We generated a double-gene knockdown plant by transforming nog1-2 with an NOG1-1-RNAi construct. Two lines, nog1-2 NOG1-1-RNAiA and nog1-2 NOG1-1-RNAiB, which showed 50\% NOG1-1 downregulation, were selected for further experiments (Fig. S5C). In addition, NOG1-1 was overexpressed in Arabidopsis Col-0 (NOG1-1 OE).

The double-gene knockdown lines along with Col-0, single-gene knockdown and overexpressor lines were flood-inoculated ${ }^{27}$ with Pstab (Fig. 4A) or Psm (Fig. 4B). NOG1-1-RNAi lines and the double-gene knockdown lines had $\sim 10$-fold increased bacterial growth when compared to Col-0 (Fig. 4A). The nog1-2 line did not support more growth of Pstab at $3 \mathrm{dpi}$ even though $\sim 10$-fold increase in bacterial growth was observed at 1 dpi when compared to Col-0 (Fig. 4A). Both nog1-2 and NOG1-1-RNAi lines showed slightly enhanced susceptibility to the host pathogen Psm by supporting higher bacterial growth (Fig. 4B). Double-gene knockdown lines showed an additive effect in comparison with single-gene knockdown lines for hyper-susceptibility to host pathogen inoculation. Strikingly, NOG1-1-OE lines exhibited fewer disease symptoms and harbored fewer bacteria compared to Col-0 (Fig. 4B).

NOG1-2 is involved in the regulation of stomatal closure in response to pathogens and abiotic stimuli. NOG1-1 and NOG1-2 were induced by ABA (Fig. 3) and therefore the role of these genes in stomatal defense was studied. Arabidopsis epidermal peels were prepared from wild-type Col-0, nog1-2, NOG11-RNAi2, and NOG1-2-comp plants and treated with either ABA, Flg22, nonhost (Pstab), or host pathogen (Psm). In response to ABA, Flg22, and Pstab, NOG1-1-RNAi2, and NOG1-2-comp lines closed stomata similar to Col0 , while the nog1-2 stomata were not completely closed (Fig. 5A). Treatment with host pathogen, Psm, caused stomata to remain open in all the lines tested, because this pathogen is known to produce COR that can reopen stomata. Quantification of these results was obtained by measuring the stomatal aperture (Fig. 5B). The aperture size of stomata in Col-0, NOG1-1-RNAi2, and NOG1-2-comp lines decreased by $50 \%$ to $80 \%$ upon treatments that close stomata, while stomatal aperture in nog $1-2$, remarkably, was only reduced by $10 \%$ to $30 \%$ (Fig. $5 \mathrm{~B}$ ).

The observation that nog1-2 is defective in closing stomata during biotic stress suggested that nog1-2 could enable more pathogen entry. To test this hypothesis, epidermal peels of nog1-2, NOG1-1-RNAi2, and Col-0 were individually incubated with Psm and Pstab expressing GFPuv $v^{28}$, respectively. The bacterial entry in nog1-2 and Col-0 plants was quantified at 1 hour post inoculation (hpi) and $3 \mathrm{hpi}$. The number of host bacterial cells (Psm) was greater in nog1-2 at 1 hpi but was not different than wild-type and NOG1-1-RNAi2 at 3 hpi since the host pathogen was able to reopen stomata (Fig. 5C). Number of nonhost bacterial cells (Pstab) inside nog1-2 leaves was $\sim 10$-fold higher than in Col-0 and NOG1-1-RNAi line at both 1 and $3 \mathrm{hpi} \mathrm{(Fig.} \mathrm{5C).} \mathrm{In} \mathrm{contrast} \mathrm{to} \mathrm{nog1-2,}$ NOG1-1-RNAi lines did not show any difference in entry of bacteria through stomata when compared to Col-0 (Fig. 5C). This agrees with the results shown in Fig. 5A that the stomata closure in NOG1-1-RNAi2 in response to ABA, flg22, and nonhost bacterial pathogen (Pstab) was not altered even though NOG1-1 was highly expressed in guard cell (Fig. S4). It is possible that NOG1-1 may have a role in stomatal aperture regulation and/or development, but the transcript reduction levels in the RNAi lines is not sufficient to observe defects in stomatal aperture regulation.

NOG1-2 has GTPase activity and positively regulates bacterial pathogen- and abiotic-mediated guard cell signalling. To examine the role of NOG1-2, the biochemical activity of recombinant and purified AtNOG1-2 was assessed in a hydrolysis and phosphate release assay (Fig. 6A, left panel and Fig. S6D). The JAZ9 protein that has been shown to play a role in stomatal closure ${ }^{29}$, which has no known GTPase domain, was used as negative control. Our results show that NOG1-2 has GTP-binding and GTPase activity. Furthermore, NOG1-2 was strongly expressed in guard cells of the Arabidopsis transgenic plants expressing AtNOG1-2-GFP fusion driven by AtNOG1-2 promoter (Fig. 6A, right panel). NOG1-2 was localized to the nucleus in guard cells of Arabidopsis. In N. benthamiana, NbNOG1-GFP (35S::NOG1) was localized to the nuclei and cytoplasmic membrane (Fig. 6A).

To further examine the involvement of NOG1-2 in JA- and ABA-mediated signaling pathway, the sensitivity of nog1-2 to MeJA and ABA was tested. As reported earlier ${ }^{30}$, several JAZ ( $j a z 9$ used in this study) mutants showed sensitivity to MeJA because of the functional compensation by other JAZs, while coil mutant showed less sensitivity to MeJA (Fig. 6B). Interestingly, nog 1-2 also showed reduced sensitivity to MeJA. It was also found that nog 1-2 plants are more susceptible to drought stress and less response to ABA, suggesting that NOG1-2 is involved in JA and $\mathrm{ABA}$ signaling pathway (Fig. 6C).

In order to dissect whether NOG1-2 is closely related to other genes involved in guard cell signaling, the gene expression profiling was conducted in nog 1-2 lines in response to ABA, coronatine (COR), and host and nonhost bacterial pathogens (Fig. S7). A total of 12 functionally characterized genes for guard cell signaling such as OST1, OST2, rbohD, MPK4, MPK9, MPK12, ABI1, SLAC1, RIN4, SLAH3, CPK4 and CPK6 were determined for the expression patterns upon exposure to both abiotic and biotic stimuli in nog1-2 lines. After ABA treatment, OST2 expression was significantly increased in Col-0 at both 12 and $24 \mathrm{hr}$, but the expression was decreased in nog 1-2 at $24 \mathrm{hr}$. The expression of $M P K 4, M P K 9, A B I 1$, and CPK6 was highly upregulated in Col- 0 at $12 \mathrm{hr}$, while these genes were not notably induced in nog1-2. After treatment of COR, rbohD, MPK4, MPK12, and SLAC1 were rapidly induced in Col-0 at $12 \mathrm{hr}$, but not found in nog1-2. MPK9 and RIN4 expression was notably decreased in 
A

P. syringae pv. tabaci

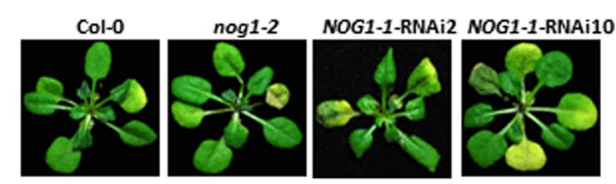

nog1-2 NOG1-1 nog1-2 NOG1 1-
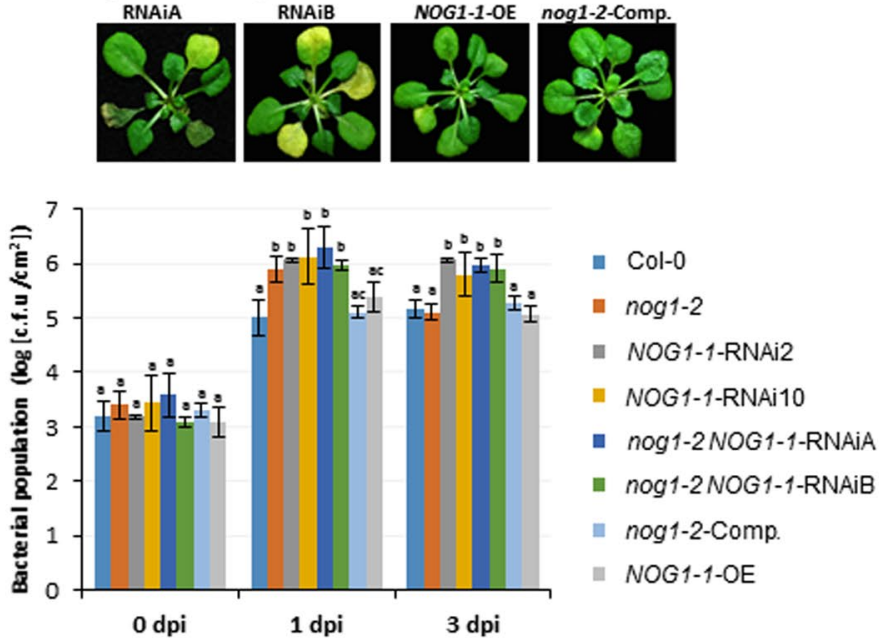

B

\section{P. syringae pv. maculicola}
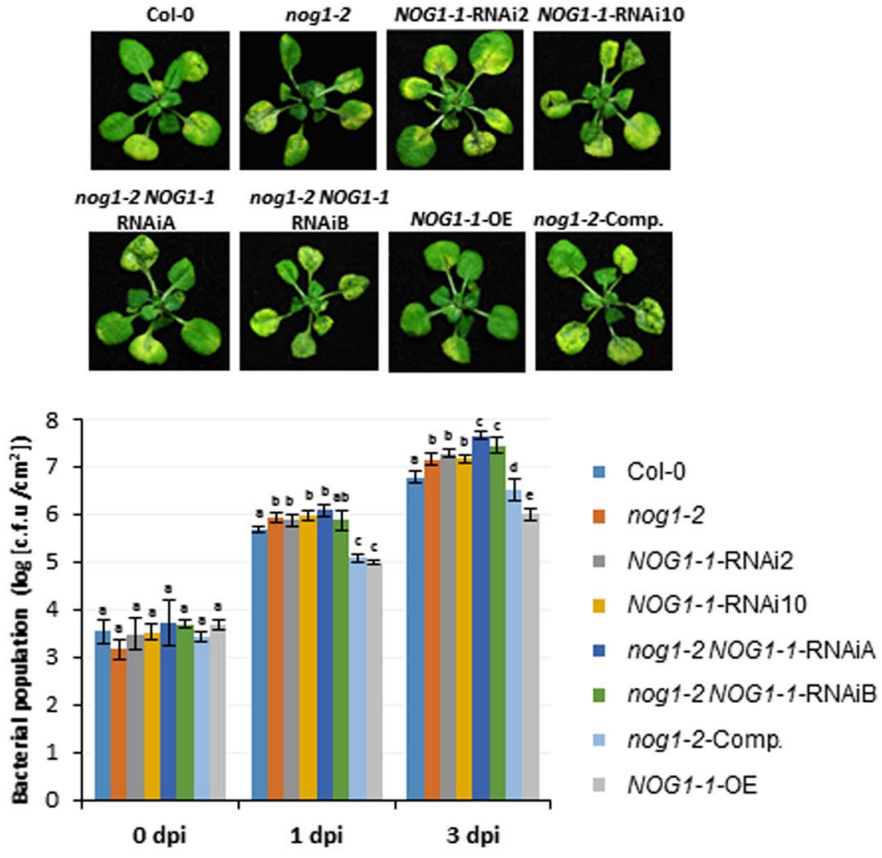

Figure 4. Arabidopsis NOG1-1-RNAi but not nog1-2 plants are compromised in nonhost resistance. (A,B) Arabidopsis wild type (Col-0), nog1-2 knockdown line, NOG1-1-RNAi, nog1-2 NOG1-1-RNAi double-gene knockdown lines, overexpression (NOG1-1-OE) and complementation lines (NOG1-2-comp) were floodinoculated with Pstab $\left(1.4 \times 10^{6} \mathrm{CFU} / \mathrm{ml}\right)(\mathrm{A})$ or Psm $\left(1 \times 10^{4} \mathrm{CFU} / \mathrm{ml}\right)(\mathbf{B})$ to assess disease symptoms (upper panel) and bacterial growth (lower panel) at 1 and 3 days post inoculation (dpi). Different letters above bars indicate a statistically significant difference within a time point using two-way ANOVA $(P<0.01)$. Error bars represent the standard deviation of three biological replications (three technical replicates for each biological replication). All experiments were conducted using T2 lines. 
A

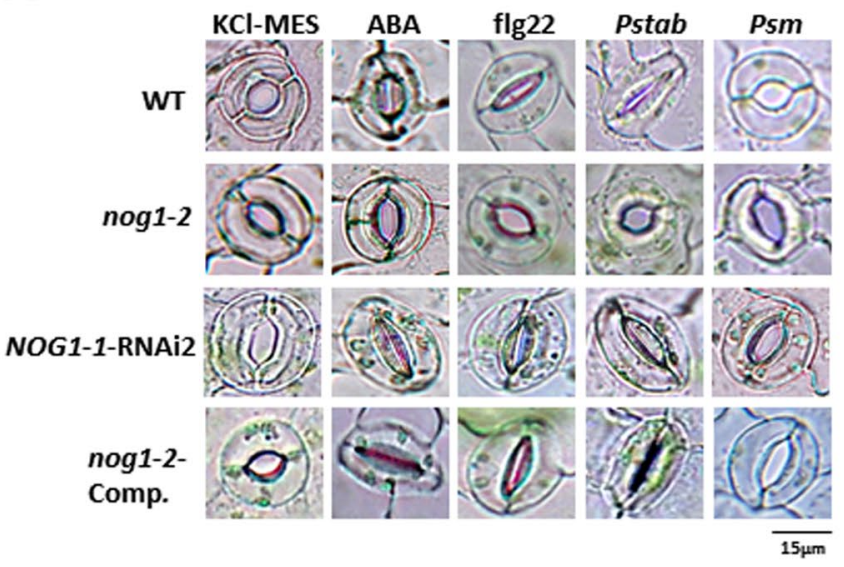

B

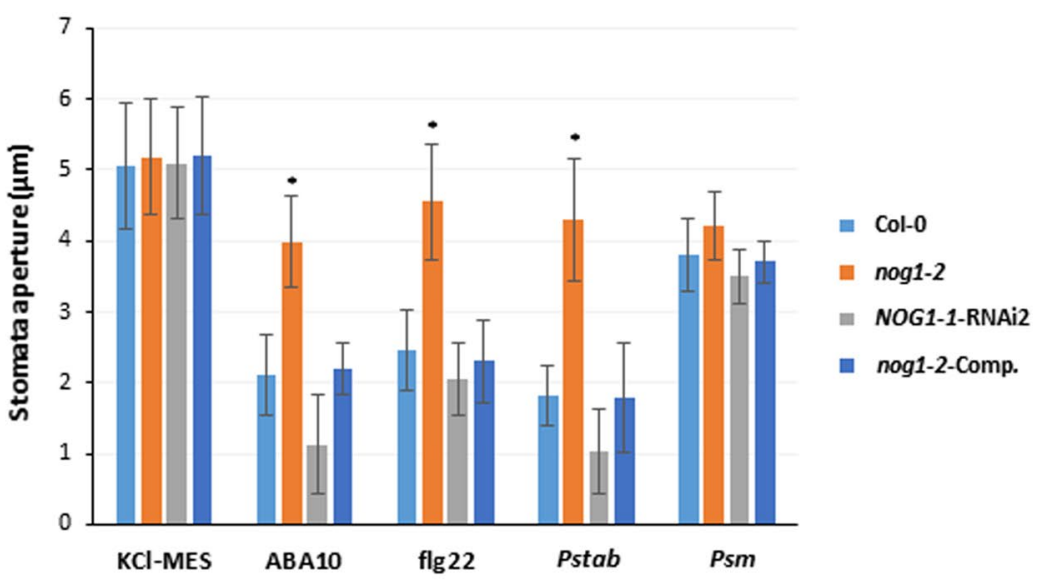

C
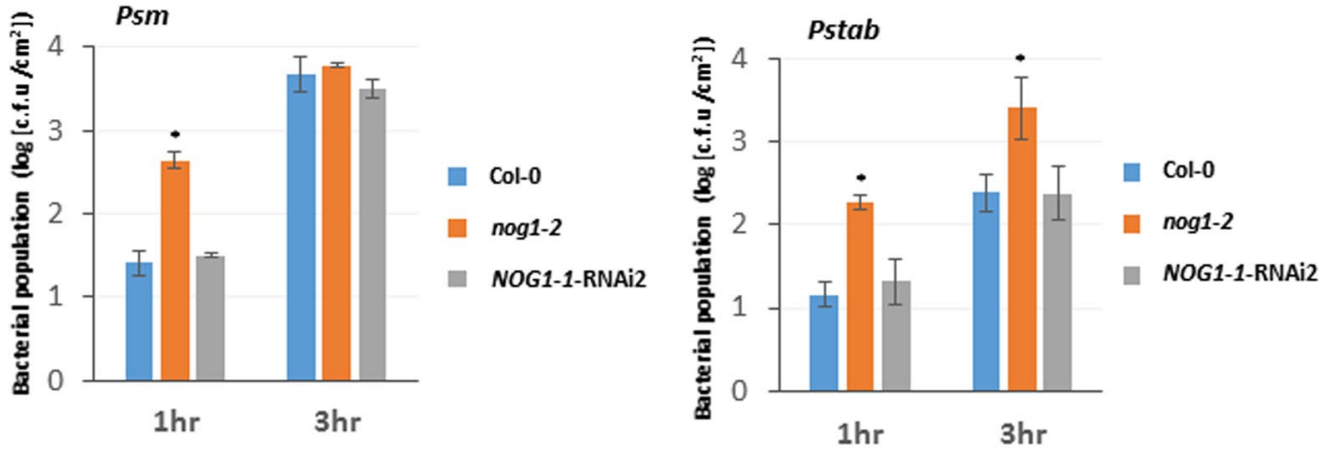

Figure 5. ABA, PAMPs, and nonhost bacterial pathogens induce stomatal closure in NOG1-2-dependent manner. (A,B) The nog1-2 line impairs ABA-, PAMPs- and nonhost-bacterial-pathogen-induced stomatal closure. To observe stomatal behavior, epidermal peels of Col-0, nog1-2, NOG1-1-RNAi2, and NOG1-2 complemented lines were treated with stomata-opening buffer (KCl-MES), ABA (10 $\mu \mathrm{M}$ or $50 \mu \mathrm{M})$, flg22 $(20 \mu \mathrm{M})$, Pstab and $P s m$ at $1 \times 10^{4} \mathrm{CFU} / \mathrm{ml}$. Microscopic images were taken $3 \mathrm{hr}$ after inoculation. The aperture size of stomata was measured after $30 \mathrm{~min}$ for ABA, $1 \mathrm{hr}$ for flg22 and LPS, and $3 \mathrm{hr}$ for Pstab and Psm. Asterisks indicate significant difference by Student's $t$-test $(P<0.05)$. Error bars indicate standard error for counting 50 stomata/each epidermal peel. Three samples were examined for each treatment, and the experiment was repeated at least three times with similar results. (C) Bacterial entry through stomata in nog1-2 and NOG1-1RNAi2 lines. To quantify bacterial entry, detached Arabidopsis leaves from wild-type Col-0 and nog 1-2 and NOG1-1-RNAi2 were floated in bacterial suspensions $\left(1 \times 10^{4} \mathrm{CFU} / \mathrm{ml}\right)$ of the nonhost pathogen $($ Pstab $)$ or host pathogen (Psm). After $1 \mathrm{hpi}$ and $3 \mathrm{hpi}$, leaves were surface-sterilized with $10 \%$ bleach, ground, serially diluted and plated on KB media (B). After 2 days, the number of bacterial colony was counted. This experiment was repeated three times and showed similar results: five replications in each experiment. Asterisks indicate significant difference by Student's $t$-test $(P<0.05)$. 
A

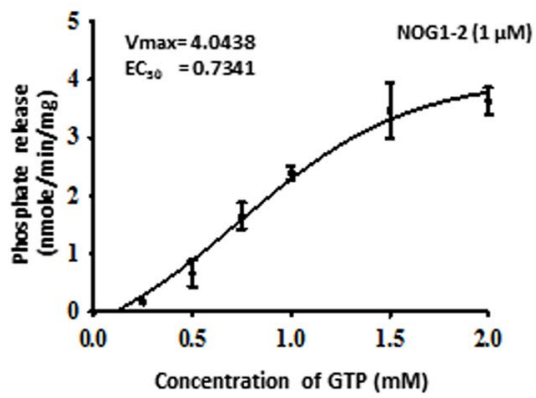

pATNOG1-2-ATNOG1-2::GFP

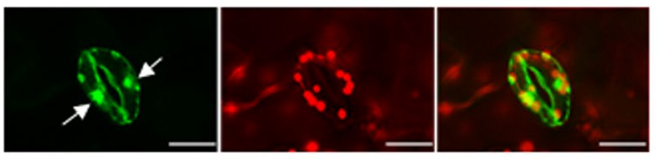

p35S-NbNOG1::GFP

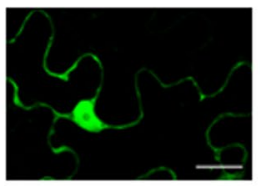

B
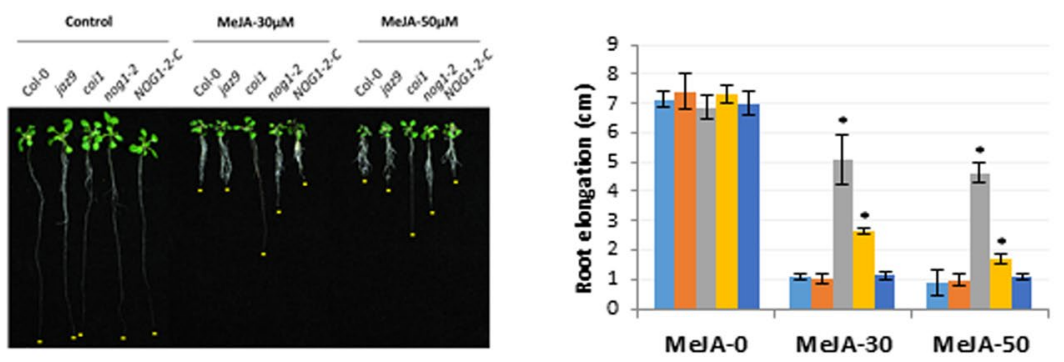

- Col-0

- jaz?

| coi1

III nog1-2

NOG1-2-Comp.

\section{C}
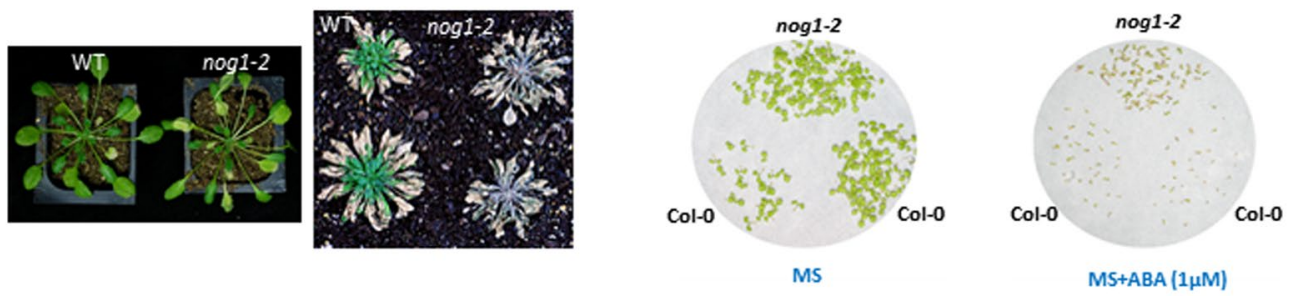

Figure 6. NOG1-2 has GTPase activity and is functionally involved in JA- and ABA-mediated signaling pathway. (A) Left Panel: Rate of Pi release due to the GTPase activity of NOG1-2 protein $(1 \mu \mathrm{M})$ in the presence of varying concentrations of GTP. Experiments were repeated three times, and data were averaged. Error bars represent the mean \pm S.E. Right panel: The transgenic Arabidopsis or N. benthamiana plants expressing AtNOG1-2-GFP under native promoter of AtNOG1-2 or NbNOG1-GFP under 35 S promoter, respectively. Arrows represent nuclei in guard cells. One week of seedlings were observed for the localization of AtNOG1-2 under confocal laser microscopy. Scale bar is $10 \mu \mathrm{M}$. Atnog1-2 is less sensitive to JA than Col-0. (B) Atnog1-2 line, compared to wild-type Col-0, is less sensitive to JA. Seeds of different Arabidopsis lines were grown in $1 / 2$ MS medium plates with or without 30 and $50 \mu \mathrm{M}$ of MeJA, and 7 days later root lengths were measured. Three independent experiments were done, with at least 10 seedlings for each line. Bars represent means \pm SD. Asterisks indicate significant difference from Col- 0 by Student's $t$-test $(P<0.05)$. (C) The mutation of AtNOG1-2 increases sensitivity to drought stress and ABA. Wild-type (Col-0) and nog1-2 plants were grown for four weeks $\left(21^{\circ} \mathrm{C} / 14 \mathrm{hr}\right.$ day and $18^{\circ} \mathrm{C} / 10 \mathrm{hr}$ night $)$, then plants were dehydrated until drought symptom appeared. After leaves were completely collapsed, plants were re-watered to revive. nog1-2 seedlings are less sensitive to ABA. Seedlings of Col-0 and nog1-2 were grown in MS or MS with ABA (1uM) for 2-weeks.

nog1-2 at $24 \mathrm{hr}$. After host pathogen (Psm) infection, the expression of MPK9 was significantly increases in Col-0 at $24 \mathrm{hr}$; however, this gene was not upregulated in nog1-2. The similar pattern was also found for MPK12.

Transcriptome analysis reveals the regulation of NOG1-1 and NOG1-2 in plant innate immunity against bacterial pathogens. The transcriptome analysis was performed in Col-0, NOG1-1 RNAi, and nog 1-2 lines without any treatment of biotic and abiotic stimuli using Affymetrix GeneChip ${ }^{\circledR}$ Arabidopsis Genome Arrary (Affymetrix). A total of 161 genes were identified as differentially expressed genes (DEGs) in NOG1-1 RNAi and nog1-2 lines compared to Col-0, respectively (Table S3). For nog1-2, only 14 DEGs were identified, nine for upregulation and five for downregulation. All genes are highly related in the signaling pathway of biotic and abiotic stress responses. 


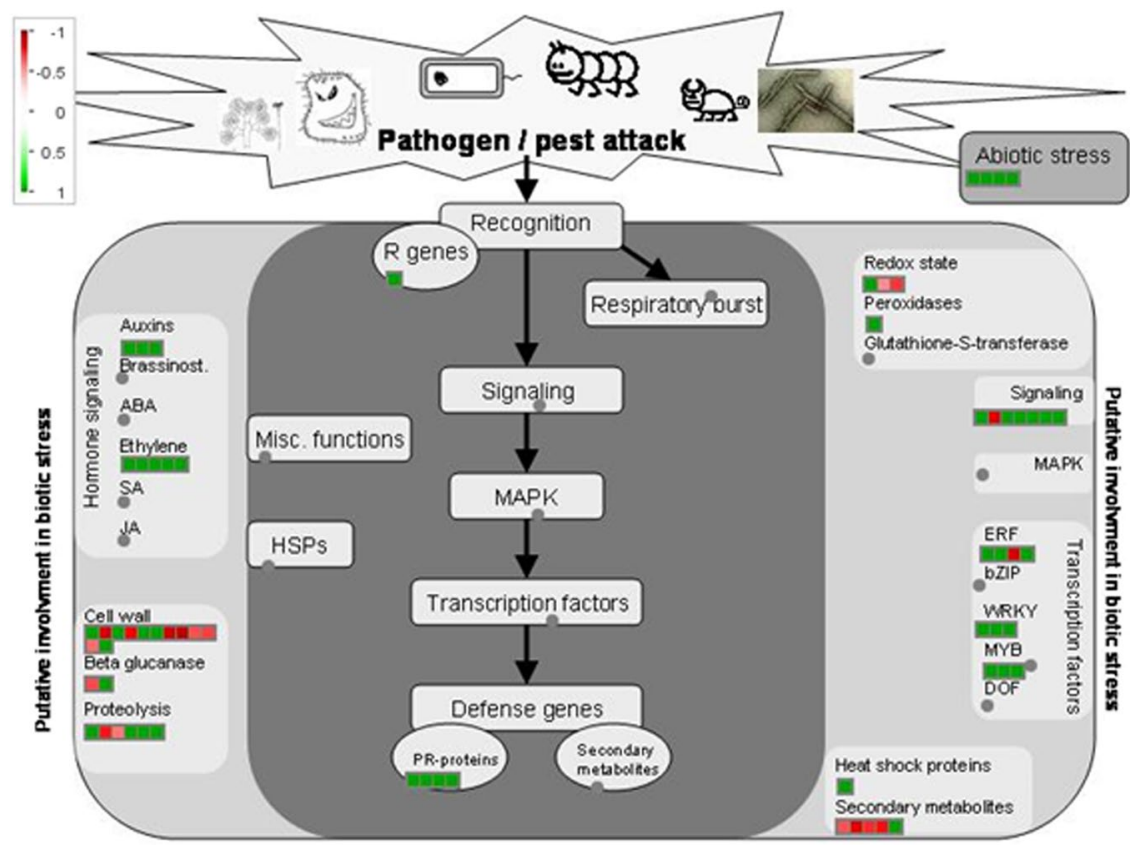

Figure 7. MAPMAN visualization of Arabidopsis Affymetrix data describing the differentially expressed genes involved in plant defense responses in NOG1-1 RNAi and nog1-2 lines. The Affymetrix microarray analysis showed a number of up- and down-regulated genes in NOG1-1 RNAi and nog1-2 lines compared to wild-type (Col-0) without treatment. MAPMAN was used to analyze the gene function and biological pathways of NOG11 and NOG1-2. Four-week old seedlings grown on half MS media were collected for RNA extraction. Three biological replicates were used for each NOG1-1 RNAi and nog1-2 without any treatments. Color patterns from red (upregulation) to green (downregulation) indicate the change of gene expression.

MAPMAN software was used to visualize the DEGs of NOG1-1 RNAi and nog1-2 to determine their putative role in plant defense. Because of very low number of DEGs in nog1-2, DEGs for both NOG1-1 RNAi and nog12 lines were pooled for the analysis. The DEGs represented in the Arabidopsis microarray were classified into different functional groups using automated and manual annotation. The MAPMAN analysis identified that the common DEGs in NOG1-1 RNAi and nog1-2 were highly responsive to biotic and abiotic stresses (Fig. 7). Most of down-regulated genes in both NOG1-1 RNA $i$ and nog1-2 are involved in the signaling pathways for abiotic and biotic defense responses. The number of DEGs was significantly higher in NOG1-1 RNAi than in nog1-2.

\section{Discussion}

This study identified a small GTP-binding protein (GTPase), NOG1, as a novel player in plant immunity against bacterial pathogens. Two copies of this gene, NOG1-1 and NOG1-2, exist in plants, and are required for nonhost resistance associated with apoplastic and stomatal defense. Stomatal closure in plants can be triggered by bacterial pathogens and PAMPs such as flg22 and LPS ${ }^{4,5,7}$. The guard cell signaling pathway involved in PAMPs- or pathogen-induced stomatal closure is still not fully understood. Only a few proteins, such as FLS2, COI1, MYC2 and MPK4, have been studied with respect to stomatal closure in response to phytobacterial pathogens ${ }^{31}$. Also, Penetration 3 (PEN3) has been demonstrated for stomatal defense against fungal pathogens in Arabidopsis ${ }^{32,33}$. The results reported here suggest that NOG1-2 may be an additional key regulator of stomatal closure in response to biotic and abiotic stimuli. Interestingly, NOG1-1 doesn't seem to play a major role in regulating stomatal closure but is involved in apoplastic defense against bacterial pathogens, indicating a possible interplay between NOG1-1 and NOG1-2 in plant innate immunity, such as regulation of stomatal opening and induction plant defense responses.

Small GTPases have been studied extensively for their role in cellular development and regulation of signal transduction in plants ${ }^{13}$. More than 100 small GTPases are known from higher eukaryotes, which are generally classified into Ras, Rho, Rab, Sar1/Arf and Ran families ${ }^{34}$. Rho and Rab small GTPases have been widely studied for their role in defense signaling against fungal and bacterial pathogens ${ }^{35}$. NOG1-1 and NOG1-2 encode small GTPases that belong to OBG family whose function in plants has never been investigated. In mammals and yeast, the orthologs of NOG1 are GTPBP4 and Nog1p, and essential for ribosome biogenesis and cell viability $^{23}$. Both GTPBP4 and Nog1p are known to be localized to the nucleus ${ }^{24}$. GTPBP4 orthologs are highly conserved within their GTPase domains (Fig. S2A) and found in many eukaryotes (http://www.genecards.org). Interestingly, NOG1/GTPBP4 orthologs are always present as a single copy in mammals, insects, and yeast, while two homologs are found in monocot and dicot plant species (http://www.phytozome.net). Only one copy of the NOG1 ortholog is present in two algae species (Chlamydomonas reinhardtii; XM_001698344 and Guillardia theta; XM_001698344), but two homologs are present in moss (Physcomitrella patens subsp. Patens; XM_001698344 
and XM_001761522). This finding suggests that higher plant species may need an additional copy of NOG1 for a plant-specific function, such as regulation of stomatal opening and early defense responses specific to plants.

The Arabidopsis genome has genes for 12 JAZ family proteins. It has been reported that single gene mutations in genes encoding JAZ2, JAZ5, JAZ7 or JAZ9 did not result in JA insensitivity as in coil mutants, suggesting functional redundancy among JAZ proteins in Arabidopsis ${ }^{30}$. Furthermore, Arabidopsis jaz1 jaz2 double mutant did not alter JA signaling ${ }^{36}$. In Arabidopsis, several JAZs have been shown to interact with COI1 ${ }^{37}$, and represses the MYC2 transcription factor to regulate JA-mediated stomatal closure ${ }^{10}$. COI1 functions as a receptor for JA and recruits JAZ proteins for ubiquitination and degradation via the $26 \mathrm{~S}$ proteosome. It is uncertain if NOG1-2 function for stomatal closure is associated with JAZ/COI1-mediated JA signaling pathway. MYC2 is another key component of the JA signaling pathway ${ }^{38}$. It has been reported that MYC2 interacts with all $12 \mathrm{JAZ}$ proteins, further suggesting the redundant function of JAZs ${ }^{39}$. MYC2 induces JA-responsive genes, and its activity is reduced by JAZ proteins. MYC2 has been shown to be phosphorylated by MPK6 in the regulation of seedling development and photomorphogenesis ${ }^{40}$. Figure 7 shows that several genes involved in MAPK signaling pathway are differentially expressed in NOG1-1 RNAi and nog1-2 lines. It will be interesting to determine if NOG1-2 can be phosphorylated by a kinase. There is evidence for the phosphorylation of small GTPases by kinases that enhance GTPase activity ${ }^{41}$.

As shown in Fig. 6, nog1-2 plants are more susceptible to drought stress and less sensitive to ABA, indicating the involvement of NOG1-2 in the guard cell signaling pathway. The expression of OST2, MPK4, MPK9, ABI1, and CPK6, which are key players in guard cell ABA signal transduction, was significantly altered in nog1-2 line after ABA treatment (Fig. S7). This finding suggests that NOG1-2 may be a key element upstream of guard cell regulating and $\mathrm{ABA}$-induced genes and interplay with a complex network of ABA signaling pathways. MPK4 is known to negatively regulate stomata open/closure against bacterial pathogens ${ }^{42}$. Our study also showed the expression changes of MPK4 in response to PAMPs and bacterial pathogens in nog1-2 line. It has been known that MPK9 and MPK12 are highly expressed during ABA-induced and $\mathrm{H}_{2} \mathrm{O}_{2}$-induced stomatal closure ${ }^{43}$. These two genes are differently expressed in nog 1-2 line when compared to Col-0, suggesting that MPK9 and MPK12 function in bacterial pathogen-induced guard cell signaling pathway.

In conclusion, we identified a novel role of NOG1 in plant innate immunity and it would be important to further investigate the mechanism of plant defense response mediated by NOG1. More interestingly, we identified the novel function of NOG1-2 for stomatal closure in response to biotic and abiotic stimuli. This warrants further investigation for the role of NOG1-2 in stomatal regulation through JA and ABA signaling. Nevertheless, identification of NOG1 as one of the key regulators of stomatal aperture and plant innate immunity will become an important avenue to better understand plant response to biotic and abiotic stresses.

\section{Methods}

Virus-induced gene silencing in $\mathbf{N}$. benthamiana and tomato plants. VIGS library used in this study for forward genetics screening was constructed using RNA from various biotic and abiotic stress inducing elicitor treated N. benthamiana plants. Agrobacterium tumefaciens GV2260 containing TRV1, TRV2::00 and TRV2::NOG1 was grown overnight on LB medium containing antibiotics (rifampicin, 25; kanamycin, 50) at $28^{\circ} \mathrm{C}$. Bacterial cells were harvested and resuspended in induction medium (10 mM MES pH 5.5; $200 \mathrm{uM}$ acetosyringone), and incubated at room temperature on an orbital shaker for $5 \mathrm{hr}$. Bacterial cultures containing TRV1 and TRV2 were mixed in equal ratios $\left(\mathrm{OD}_{600}=1\right)$ and infiltrated into $N$. benthamiana or tomato leaves using a $1 \mathrm{ml}$ needleless syringe ${ }^{44}$. The infiltrated plants were maintained in a greenhouse and used for studies 15 to 21 days post-infiltration. Table S6 has all the primer information used in this study.

Hypersensitive response analysis. For nonhost pathogens-dependent HR, the bacterial suspension in MES buffer (MES 10Mm, pH6.5) was syringe-infiltrated to fully expanded N. benthamiana leaves for determining nonhost HR cell death. For R/Avr-dependent HR, leaves were infiltrated with a mixture of Agrobacterium tumefaciens expressing Avr genes and its complementary $C f$ or Pto gene using a sterile needleless syringe. Pto and AvrPto, or $C f 9$ and $A v r C f 9$ constructs were mixed to 1:1 ratio before infiltration to $N$. benthamiana leaves. The agro-inoculated plants were maintained under standard growth condition, and HR cell death in the inoculated area was investigated and photographed.

Plant growth, pathogen inoculation, and bacterial growth assay. N. benthamiana and tomato plants were grown in greenhouse. Silenced and control N. benthamiana plants were inoculated with appropriate bacterial pathogens. Bacterial strains were grown at $28^{\circ} \mathrm{C}$ on $\mathrm{KB}$ medium containing antibiotics in the following concentrations ( $\mu \mathrm{g} / \mathrm{ml})$ : rifampicin, 50; kanamycin, 25; chloramphenicol, 25 and spectinomycin, 25 for $24 \mathrm{hr}$. To prepare bacterial inoculum, the culture media were centrifuged at $5000 \mathrm{rpm}$ for $10 \mathrm{~min}$ and resuspended in water for bacterial growth assays using vacuum infiltration and spraying. The inoculated plants were then incubated in growth chambers at 90 to $100 \%$ relative humidity for the first $24 \mathrm{~h}$.

Arabidopsis thaliana T-DNA insertion lines: SALK_043706 and SALK_072852 containing insertions in NOG1-2 were obtained from http://signal.salk.edu/cgi-bin/tdnaexpress. Wild-type Col-0 and T-DNA insertion lines were grown in $1 / 2 \mathrm{MS}$ plates in growth chamber at $21^{\circ} \mathrm{C}$ with a 14 -h photoperiod and a light intensity of about $100 \mathrm{uE} \mathrm{m}^{-2} \mathrm{sec}^{-1}$. Four-week-old plants were inoculated with appropriate host or nonhost bacterial pathogens, and bacterial growth was measured. For the bacterial growth assays in N. benthamiana and tomato, leaf samples from inoculated leaves at specific time points after inoculation were collected by using a $0.5 \mathrm{~cm}$ leaf puncher. Leaf tissues were ground in sterile water, serially diluted and plated on KB plates supplemented with appropriate antibiotics. For the bacterial growth assays in Arabidopsis after flood-inoculation, inoculated leaves were surface-sterilized with $15 \% \mathrm{H}_{2} \mathrm{O}_{2}$ for 3 min to eliminate epiphytic bacteria and then washed with sterile 
distilled water. The leaves were then homogenized in sterile distilled water, and serial dilutions were plated onto $\mathrm{KB}$ medium containing antibiotics. Bacterial growth was evaluated in three independent experiments.

Stomatal aperture measurements and bacterial entry assay. The stomatal aperture measurement experiments were performed by following the protocol available at Melotto lab, University of California Davis (http://melotto.ucdavis.edu/protocol_stomatal.htm) and the previous study ${ }^{7}$. Briefly, plants were conditioned to open stomata by placing plants under fluorescence light for at least $3 \mathrm{hr}$. Epidermal peels were then immediately floated on stomata-opening buffer $(10 \mathrm{mM}$ MES-Tris $\mathrm{pH} 6.1,10 \mathrm{mM} \mathrm{KCl})$ for $3 \mathrm{hr}$. At various time points, the epidermal peels were treated with ABA, flg22, LPS and bacterial pathogens. Epidermal peels were observed under Nikon light microscope.

To determine bacterial entry via stomata, detached leaves from 2 -week-old seedlings grown in $1 / 2$ strength MS medium were floated on bacterial suspension. After $1 \mathrm{hr}$ or $3 \mathrm{hr}$ incubation, leaf surfaces were sterilized using $10 \%$ bleach (Clorox), then observed under a fluorescent microscope or plated on KB medium after serial dilutions.

In vitro GTPase activity assay and phosphate release assay. The GTPase activity of NOG1-2 was also evaluated using the ENZchek phosphate release assay kit (Thermo Fisher Scientific, NY). Phosphate (Pi) production was detected as a change in absorbance at $360 \mathrm{~nm}$ using a Spectramax M2 spectrophotometer (Molecular Devices, Sunnyvale, CA). The amount of Pi released was estimated from the corresponding values obtained with a standard curve. Data was plotted as nanomoles of Pi released $\mathrm{min}^{-1} \mathrm{mg}^{-1}$ and fitted using nonlinear regression in SigmaPlot 11.0.

Histochemical and fluorescent microscopy analyses. To determine the expression patterns of NOG12 and NOG1-1, the promoters of NOG1-2 (1.2 kb) and NOG1-1 (0.9 kb) were fused to GUS reporter gene. NOG1$1:: G U S$ and NOG1-2::GUS transgenic seedlings were incubated with GUS staining solution at $37^{\circ} \mathrm{C}$. Staining was discarded and chlorophyll cleared by washing with 70\% ethanol and keeping the leaves in ethanol for $72 \mathrm{hrs}$. GUS activity was analyzed by bright-field transmitted light microscopy, and images were taken by digital camera (Nikon). Confocal analysis of GFP expression was performed using confocal microscope (Biorad, CA).

Development of transgenic lines. To complement the nog 1-2 knockdown line, the full length of NOG1-2 coding region was cloned into pMDC162, controlled by NOG1-2 native promoter. This construct was transformed to GV3101, and transferred into nog1-2 using Arabidopsis floral dip transformation. To knock-down NOG1-1 in Col-0, the partial sequence of NOG1-1 (approximately $400 \mathrm{bp}$ ) were selected using pssRNAit program (http://plantgrn.noble.org/pssRNAit/). This fragment was cloned into RNAi vector (Invitrogen, NY) and transformed using Arabidopsis floral dip transformation. To make double-gene knockdown line of NOG1-2, NOG1-1, NOG1-1 RNAi construct was transformed into nog1-2. To examine the localization of NOG1-2, the full length coding region of both genes were cloned into either pMDC45 or pMDC83.

RNA extraction and quantitative real-time PCR. Total RNA was purified from Arabidopsis leaves infiltrated with water (mock control), nonhost pathogen P. syringae pv. tabaci (Pstab), or host pathogen P. syringae pv. maculicola (Psm). Total RNA was extracted using TRIzol (Invitrogen), and 2 treated or inoculated leaves were pooled to represent one biological replicate. Total RNA was treated with DNase I (Invitrogen), and $1 \mu \mathrm{g}$ RNA was used to generate cDNA using Superscript III reverse transcriptase (Invitrogen) and oligo d(T)15-20 primers. The cDNA (1:20) was then used for real-time quantitative PCR using Power SYBR Green PCR master mix (Applied Biosystems, Foster City, CA, USA) with an ABI Prism 7900 HT sequence detection system (Applied Biosystems). Primers specific for AtUBQ5 was used to normalize small differences in template amounts. Average Cycle Threshold (CT) values calculated using Sequence Detection Systems (version 2.2.2; Applied Biosystems) from duplicate samples were used to determine the fold expression relative to controls. All primers used are shown in Table S4.

Transcriptome analysis of nog 1-1 and nog1-2 using Arabidopsis microarray. Arabidopsis seedlings were grown for seven days on $1 / 2 \mathrm{MS}$ in controlled conditions with a $16 \mathrm{hr}$ light, $8 \mathrm{hr}$ dark cycle at $24^{\circ} \mathrm{C}$. Total RNA from three biological replicates of NOG1-1 RNAi, nog1-2, and Col-0 leaves were isolated and cleaned by using the Rnaeasy MinElute Cleanup Kit (Qiagen, WN) and used for two-channel microarray. RNA labelling and hybridization to Affymetrix ATH1 arrays were performed as described in the Affymetrix manual. Data normalization between chips was conducted using RMA (Robust Multichip Average) ${ }^{45}$. Gene selections based on Associative T-test were made using Matlab (MathWorks, Natick, MA) ${ }^{46}$. In this method, the background noise presented between replicates and technical noise during microarray experiments was measured by the residual presented among a group of genes whose residuals are homoscedastic. Genes whose residuals between the compared sample pairs that are significantly higher than the measured background noise level were considered to be differentially expressed. A selection threshold of 2 for up-regulated and 1.5 times for down-regulated and a Bonferroni-corrected $\mathrm{P}$ value threshold of 2.19202E-06 were used for further analysis. The Bonferroni-corrected $\mathrm{P}$ value threshold was derived from $0.05 / \mathrm{N}$ in these analyses, where $\mathrm{N}$ is the number of probes sets (22810) on the chip.

Data Availability Statement. All the data presented in the manuscript will be made publicly available.

\section{References}

1. Senthil-Kumar, M. \& Mysore, K. S. Nonhost resistance against bacterial pathogens: retrospectives and prospects. Annu Rev Phytopathol 51, 407-427, doi:10.1146/annurev-phyto-082712-102319 (2013).

2. Gill, U. S., Lee, S. \& Mysore, K. S. Host versus nonhost resistance: distinct wars with similar arsenals. Phytopathology 105, 580-587, doi:10.1094/phyto-11-14-0298-rvw (2015).

3. Arnaud, D. \& Hwang, I. A Sophisticated Network of Signaling Pathways Regulates Stomatal Defenses to Bacterial Pathogens. Molecular plant 8, 566-581, doi:10.1016/j.molp.2014.10.012 (2015). 
4. Lee, S., Ishiga, Y., Clermont, K. \& Mysore, K. S. Coronatine inhibits stomatal closure and delays hypersensitive response cell death induced by nonhost bacterial pathogens. PeerJ 1, e34 (2013).

5. Lee, S., Yang, D. S., Uppalapati, S. R., Sumner, L. W. \& Mysore, K. S. Suppression of plant defense responses by extracellular metabolites from Pseudomonas syringae pv. tabaci in Nicotiana benthamiana. BMC plant biology 13, 65, doi:10.1186/1471-2229-1365 (2013).

6. Melotto, M., Underwood, W. \& He, S. Y. Role of stomata in plant innate immunity and foliar bacterial diseases. Annu Rev Phytopathol 46, 101-122, doi:10.1146/annurev.phyto.121107.104959 (2008).

7. Melotto, M., Underwood, W., Koczan, J., Nomura, K. \& He, S. Y. Plant stomata function in innate immunity against bacterial invasion. Cell 126, 969-980, doi:10.1016/j.cell.2006.06.054 (2006).

8. McLachlan, D. H., Kopischke, M. \& Robatzek, S. Gate control: guard cell regulation by microbial stress. New Phytologist 203, 1049-1063, doi:10.1111/nph.12916 (2014).

9. Daszkowska-Golec, A. \& Szarejko, I. Open or close the gate - stomata action under the control of phytohormones in drought stress conditions. Frontiers in plant science 4, 138, doi:10.3389/fpls.2013.00138 (2013).

10. Chini, A., Boter, M. \& Solano, R. Plant oxylipins: COI1/JAZs/MYC2 as the core jasmonic acid-signalling module. The FEBS journal 276, 4682-4692, doi:10.1111/j.1742-4658.2009.07194.x (2009).

11. Pauwels, L. et al. NINJA connects the co-repressor TOPLESS to jasmonate signalling. Nature 464, 788-791, doi:10.1038/nature08854 (2010).

12. Urano, D., Chen, J. G., Botella, J. R. \& Jones, A. M. Heterotrimeric G protein signalling in the plant kingdom. Open Biol 3, 120186, doi:10.1098/rsob.120186 (2013)

13. Yang, Z. Small GTPases: versatile signaling switches in plants. Plant Cell 14 Suppl, S375-388 (2002).

14. Cherfils, J. \& Zeghouf, M. Regulation of small GTPases by GEFs, GAPs, and GDIs. Physiological reviews 93, 269-309, doi:10.1152/ physrev.00003.2012 (2013).

15. Kawano, Y., Kaneko-Kawano, T. \& Shimamoto, K. Rho family GTPase-dependent immunity in plants and animals. Frontiers in plant science 5, 522, doi:10.3389/fpls.2014.00522 (2014).

16. Roos, J., Bejai, S., Oide, S. \& Dixelius, C. RabGAP22 is required for defense to the vascular pathogen Verticillium longisporum and contributes to stomata immunity. PloS one 9, e88187, doi:10.1371/journal.pone.0088187 (2014).

17. Antignani, V. et al. Recruitment of PLANT U-BOX 13 and the PI4Kbeta1/beta2 phosphatidylinositol-4 kinases by the small GTPase RabA4B plays important roles during salicylic acid-mediated plant defense signaling in Arabidopsis. The Plant cell 27, 243-261, doi:10.1105/tpc.114.134262 (2015).

18. Hong, M. J. et al. Rice Rab11 is required for JA-mediated defense signaling. Biochemical and biophysical research communications 434, 797-802, doi:10.1016/j.bbrc.2013.04.014 (2013).

19. Verstraeten, N., Fauvart, M., Versees, W. \& Michiels, J. The universally conserved prokaryotic GTPases. Microbiology and molecular biology reviews: $M M B R$ 75, 507-542, second and third pages of table of contents, doi:10.1128/mmbr.00009-11 (2011).

20. Suwastika, I. N. et al. Evidence for lateral gene transfer (LGT) in the evolution of eubacteria-derived small GTPases in plant organelles. Frontiers in plant science 5, 678, doi:10.3389/fpls.2014.00678 (2014).

21. Mittenhuber, G. Comparative genomics of prokaryotic GTP-binding proteins (the Era, Obg, EngA, ThdF (TrmE), YchF and YihA families) and their relationship to eukaryotic GTP-binding proteins (the DRG, ARF, RAB, RAN, RAS and RHO families). Journal of molecular microbiology and biotechnology 3, 21-35 (2001).

22. Suwastika, I. N. et al. Evidence for lateral gene transfer (LGT) in the evolution of eubacteria-derived small GTPases in plant organelles. Frontiers in plant science 5, 678, doi:10.3389/fpls.2014.00678 (2014).

23. Fuentes, J. L., Datta, K., Sullivan, S. M., Walker, A. \& Maddock, J. R. In vivo functional characterization of the Saccharomyces cerevisiae 60S biogenesis GTPase Nog1. Mol Genet Genomics 278, 105-123, doi:10.1007/s00438-007-0233-1 (2007).

24. Kallstrom, G., Hedges, J. \& Johnson, A. The putative GTPases Noglp and Lsg1p are required for 60S ribosomal subunit biogenesis and are localized to the nucleus and cytoplasm, respectively. Mol Cell Biol 23, 4344-4355 (2003).

25. Sano, S. et al. Light-dependent expression of flg22-induced defense genes in Arabidopsis. Frontiers in plant science 5, 531, doi:10.3389/fpls.2014.00531 (2014).

26. Wang, K., Senthil-Kumar, M., Ryu, C. M., Kang, L. \& Mysore, K. S. Phytosterols play a key role in plant innate immunity against bacterial pathogens by regulating nutrient efflux into the apoplast. Plant Physiol 158, 1789-1802, doi:10.1104/pp.111.189217 (2012).

27. Ishiga, Y., Ishiga, T., Uppalapati, S. R. \& Mysore, K. S. Arabidopsis seedling flood-inoculation technique: a rapid and reliable assay for studying plant-bacterial interactions. Plant Methods 7, 32, doi:10.1186/1746-4811-7-32 (2011).

28. Wang, K., Kang, L., Anand, A., Lazarovits, G. \& Mysore, K. S. Monitoring in planta bacterial infection at both cellular and wholeplant levels using the green fluorescent protein variant GFPuv. The New phytologist 174, 212-223, doi:10.1111/j.1469-8137.2007.01999.x (2007).

29. Zhou, Z. et al. An Arabidopsis Plasma Membrane Proton ATPase Modulates JA Signaling and Is Exploited by the Pseudomonas syringae Effector Protein AvrB for Stomatal Invasion. The Plant cell, doi:10.1105/tpc.15.00466 (2015).

30. Demianski, A. J., Chung, K. M. \& Kunkel, B. N. Analysis of Arabidopsis JAZ gene expression during Pseudomonas syringae pathogenesis. Molecular plant pathology 13, 46-57, doi:10.1111/j.1364-3703.2011.00727.x (2012).

31. Kazan, K. \& Lyons, R. Intervention of Phytohormone Pathways by Pathogen Effectors. Plant Cell 26, 2285-2309, doi:10.1105/ tpc.114.125419 (2014).

32. Stein, M. et al. Arabidopsis PEN3/PDR8, an ATP binding cassette transporter, contributes to nonhost resistance to inappropriate pathogens that enter by direct penetration. The Plant cell 18, 731-746, doi:10.1105/tpc.105.038372 (2006).

33. Underwood, W. \& Somerville, S. C. Perception of conserved pathogen elicitors at the plasma membrane leads to relocalization of the Arabidopsis PEN3 transporter. Proceedings of the National Academy of Sciences of the United States of America 110, 12492-12497, doi:10.1073/pnas.1218701110 (2013).

34. Vernoud, V., Horton, A. C., Yang, Z. \& Nielsen, E. Analysis of the small GTPase gene superfamily of Arabidopsis. Plant physiology 131, 1191-1208, doi:10.1104/pp.013052 (2003).

35. Craddock, C., Lavagi, I. \& Yang, Z. New insights into Rho signaling from plant ROP/Rac GTPases. Trends Cell Biol 22, 492-501, doi:10.1016/j.tcb.2012.05.002 (2012).

36. Grunewald, W. et al. Expression of the Arabidopsis jasmonate signalling repressor JAZ1/TIFY10A is stimulated by auxin. EMBO Rep 10, 923-928, doi:10.1038/embor.2009.103 (2009).

37. Melotto, M. et al. A critical role of two positively charged amino acids in the Jas motif of Arabidopsis JAZ proteins in mediating coronatine- and jasmonoyl isoleucine-dependent interactions with the COI1 F-box protein. The Plant journal: for cell and molecular biology 55, 979-988, doi:10.1111/j.1365-313X.2008.03566.x (2008).

38. Zhai, Q. et al. Phosphorylation-coupled proteolysis of the transcription factor MYC2 is important for jasmonate-signaled plant immunity. PLoS genetics 9, e1003422, doi:10.1371/journal.pgen.1003422 (2013)

39. Fernandez-Calvo, P. et al. The Arabidopsis bHLH transcription factors MYC3 and MYC4 are targets of JAZ repressors and act additively with MYC2 in the activation of jasmonate responses. Plant Cell 23, 701-715, doi:10.1105/tpc.110.080788 (2011).

40. Sethi, V., Raghuram, B., Sinha, A. K. \& Chattopadhyay, S. A mitogen-activated protein kinase cascade module, MKK3-MPK6 and MYC2, is involved in blue light-mediated seedling development in Arabidopsis. The Plant cell 26, 3343-3357, doi:10.1105/ tpc.114.128702 (2014).

41. Unger, H. \& van Golen, K. in The Rho GTPases in Cancer (ed Kenneth Golen) Ch. 10, 155-162 (Springer New York, 2010). 
42. Petersen, M. et al. Arabidopsis map kinase 4 negatively regulates systemic acquired resistance. Cell 103, 1111-1120 (2000).

43. Jammes, F. et al. MAP kinases MPK9 and MPK12 are preferentially expressed in guard cells and positively regulate ROS-mediated ABA signaling. Proceedings of the National Academy of Sciences of the United States of America 106, 20520-20525, doi:10.1073/ pnas.0907205106 (2009).

44. Senthil-Kumar, M. \& Mysore, K. S. Tobacco rattle virus-based virus-induced gene silencing in Nicotiana benthamiana. Nature protocols 9, 1549-1562, doi:10.1038/nprot.2014.092 (2014).

45. Irizarry, R. A. et al. Exploration, normalization, and summaries of high density oligonucleotide array probe level data. Biostatistics (Oxford, England) 4, 249-264, doi:10.1093/biostatistics/4.2.249 (2003).

46. Dozmorov, I. \& Centola, M. An associative analysis of gene expression array data. Bioinformatics 19, 204-211, doi:10.1093/ bioinformatics/19.2.204 (2003).

\section{Acknowledgements}

This work was funded by the Noble Research Institute, LLC. The authors thank Drs. Elison Blancaflor and Jin Nakashima for assistance with cellular imaging, Takako Ishiga for assistance with inoculations of tomato plants, Joohyun Lee for providing technical assistance for drought assay, and Jacquelyn Kelley for editing the manuscript.

\section{Author Contributions}

S.L. and K.M. designed experiments, M.S., M.K., C.R., Y.T., S.O., S.C., H.L., Y.I. performed the experiments and analyses. R.A., S.P. and K.M. conducted data analysis and interpretation throughout the study. All authors contributed to writing of the manuscript.

\section{Additional Information}

Supplementary information accompanies this paper at doi:10.1038/s41598-017-08932-9

Competing Interests: The authors declare that they have no competing interests.

Publisher's note: Springer Nature remains neutral with regard to jurisdictional claims in published maps and institutional affiliations.

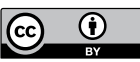

Open Access This article is licensed under a Creative Commons Attribution 4.0 International License, which permits use, sharing, adaptation, distribution and reproduction in any medium or format, as long as you give appropriate credit to the original author(s) and the source, provide a link to the Creative Commons license, and indicate if changes were made. The images or other third party material in this article are included in the article's Creative Commons license, unless indicated otherwise in a credit line to the material. If material is not included in the article's Creative Commons license and your intended use is not permitted by statutory regulation or exceeds the permitted use, you will need to obtain permission directly from the copyright holder. To view a copy of this license, visit http://creativecommons.org/licenses/by/4.0/.

(c) The Author(s) 2017 